\title{
RESUMO
}

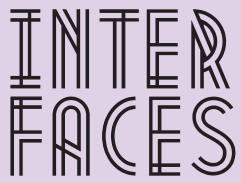

DOI: 10.17564/2316-3828.2020v8n3p483-496

ISSN Digital: 2316-3828

ISSN Impresso: 2316-333X

MAnites

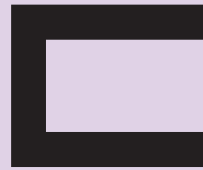

EDUCAÇÃO

CIENTÍFICAS

\section{O ESCUTAR DO SILÊNCIO - O QUE ESTÁ POR TRÁS DA MUDEZ DA BNCC SOBRE AS ESTRUTURAS DE GÊNERO}

\section{LISTENNNG TO SILENCE - WHAT IS BEHIND THE BNCC'S MUTENESS ABOUT GENDER STRUCTURES}

\section{ESCUCHAREL SLIENCIO - LO QUE HAY DETRÁS DEL SLLENCIO DE LABNCC EN LAS ESTRUCTURAS DE GÉNERO}

Carla Chagas Ramalho ${ }^{1}$ José Jairo Vieira ${ }^{2}$
As políticas públicas educacionais surgem com 0 propósito de naturalizar fenômenos sociais com consentido pelo Estado. Logo, são políticas que buscam não uma revolução social, mas que buscam amenizar crises que são produzidas, muitas vezes pelo próprio sistema político e ideológico que nos baseia. Assim, este artigo objetivou analisar o que o silêncio sobre a temática gênero na Base Nacional Comum Curricular (BNCC) tem a nos dizer. Para alcançarmos este objetivo, utilizamos como metodologia a análise documental, nos embasamos na BNCC. Alcançamos como resultados a confirmação da ausência da temática sobre a estrutura de gênero na sociedade na BNCC, mas confirmamos que este silêncio não significa um negligenciamento sobre o assunto, mas sim uma confirmação e apoio para a naturalização das estruturas atuais sobre as desigualdades de gênero. Confirmando como essas desigualdades baseiam e fortificam a nossa sociedade capitalista, que tem como propósito a exploração de uma classe ou grupo de pessoas sobre outras. Concluímos que esta visão das questões de gênero deve ser enaltecida e ampliada, com o intuito de um olhar panorâmico sem segmentações sobre gênero e as demais estruturas sociais.

\section{PALAVRAS-CHAVE}

Gênero. Políticas Públicas Educacionais. Sociedade. 
Educational public policies arise with the purpose of naturalizing social phenomena with the consent of the state. Therefore, they are policies that seek not a social revolution, but seek to alleviate crises that are produced, often by the very political and ideological system that underlies us. Thus, this article aimed to analyze what the silence on the theme gender in the Common National Curriculum Base (BNCC) has to tell us. To achieve this goal, we use document analysis as a methodology, based on the BNCC. As a result, we have confirmed the absence of the issue of gender structure in society at the BNCC, but we confirm that this silence does not mean neglecting the issue, but rather confirming and supporting the naturalization of current structures on gender inequalities. Confirming how these inequalities underlie and fortify our capitalist society, which aims to exploit one class or group of people over another. We conclude that this view of gender issues should be enhanced and broadened, with the aim of a panoramic look without segmentation on gender and other social structures.

\section{KEYWORDS}

Gender. Educational Public Policies. Society

\section{RESUMEN}

Las políticas públicas educativas surgen con el propósito de naturalizar los fenómenos sociales con el consentimiento del estado. Por lo tanto, son políticas que no buscan una revolución social, sino que buscan aliviar las crisis que se producen, a menudo por el sistema político e ideológico que nos subyace. Por lo tanto, este artículo tuvo como objetivo analizar qué nos dice el silencio sobre el tema de género en la Base Nacional Comum Curricular (BNCC). Para lograr este objetivo, utilizamos el análisis de documentos como metodología, basada en el BNCC. Como resultado, hemos confirmado la ausencia del problema de la estructura de género en la sociedad en el BNCC, pero confirmamos que este silencio no significa descuidar el problema, sino más bien confirmar y apoyar la naturalización de las estructuras actuales sobre las desigualdades de género. Confirmando cómo estas desigualdades subyacen y fortalecen nuestra sociedad capitalista, cuyo objetivo es explotar a una clase o grupo de personas sobre otra. Llegamos a la conclusión de que esta visión de las cuestiones de género debe mejorarse y ampliarse, con el objetivo de una visión panorámica sin segmentación sobre género y otras estructuras sociales. 


\section{PALABRAS CLAVE}

Género; Políticas públicas educativas; Sociedad

\section{INTRODUCÇÃO}

As escolas são instituições sociais que refletem questões e problemáticas sociais em âmbitos mais globais. São espaços onde há disputas de poderes e, por este motivo, não é um local pacífico ou apático. 0 ambiente escolar é um recinto contraditório e importante para manutenção e renovação de padrões sociais (RAMOS, 2013). Por este motivo existem normatizações que estimulam e buscam nortear ações dentro dessas instituições, para elas se refletirem na sociedade.

Algumas dessas normatizações surgem no formato de legislações, parâmetros, bases, currículos, entre outros e são denominadas como políticas educacionais. Essas políticas podem ter abrangência micro ou macro, mas com um claro intuito de estimular ações dos alunos e alunas, futuros cidadãos e cidadãs, no espaço coletivo. Por este motivo, devemos ter um olhar atento e crítico para essas políticas que, muitas vezes, são realizadas sem a participação efetiva da comunidade escolar e são trazidas de cima para baixo, buscando uma aplicação irreal para o ambiente escolar (ARROYO, 2010).

Com este intuito investigativo, o presente artigo vem analisar o que o silêncio sobre a temática gênero na Base Nacional Comum Curricular (BNCC) tem a nos dizer. De que forma essa quietude vem reverberar na sociedade atual, retratando padronizações culturais que refletem nas questões políticas, econômicas e sociais.

Compreendemos que a análise documental nos dará suporte para alcançar este objetivo, pois “[...] as fontes documentais tornam-se importantes para detectar mudanças na população, estrutura social, nas atitudes e valores sociais etc. (GIL, 2008, p. 154). Utilizaremos como instrumento de investigação principal a BNCC com o intuito de decifrar por meio dessa política pública educacional questões sociais latentes no cenário atual brasileiro.

Justificamos a importância deste estudo no entendimento que toda política educacional possui claras funções políticas (como pode por vezes passar despercebido, apesar da obviedade linguística) e que optar por não fazer parte da agenda educacional nacional a temática gênero tem desdobramentos diretos na vida pública e privada do nosso corpo físico e social.

\section{SOCIEDADE GENERIFICADA}

O intuito deste tópico é mostrar como falar sobre gênero é algo intrínseco ao falar sobre sociedade ou qualquer tipo de relação e contato pessoal. 0 gênero forma e é formador de gestos, gostos, atitudes e padrões sociais considerados como esperados para todos os corpos sexuados. 
Gênero é uma forma específica de corporificação social. A característica distintiva do gênero é que este se refere a estruturas corporais e processos ligados à reprodução humana. Gênero envolve um conjunto de práticas sociais humanas - incluindo cuidados com crianças, parto, interação sexual - que mostram as capacidades de corpos humanos de parir, dar leite, dar e receber prazer sexual. Só podemos começar a entender o gênero se compreendermos o quão próximo os processos sociais e corporais se encontram. Nascemos em sangue e dor e nascemos em uma ordem social. (CONNELL, 2015, p. 113).

Assim, deixamos claro que há uma influência materialmente física de características sexuais, as quais têm um peso e valores construídos por padrões sociais que, fique claro, não são fixos e nem imutáveis. Como há inconstância das demais bases sociais, o gênero também não destoa dessa possibilidade de variabilidade. 0 que não transforma essas características como fluida ou como opção de escolha performativa. A prática de ações de gênero é reconhecida por ações repetitivas (que podem sofrer variabilidade no processo), logo, não podemos designar as características de gênero como uma realidade preexistente que se acopla de forma pacífica a corpos sexuais (CONNELL, 2015).

Esta prática social generificada atua dentro de padrões econômicos, políticos e sociais esperados. Por exemplo, relacionar o local da mulher no mercado de trabalho, não está dissociado de definir suas funções no espaço privado e vice versa. Importante salientar que somos seres com vontades, consciência e que sofremos constantes influências sociais, por isso, tais demandas não são acatadas de forma depositária, como fossemos seres apáticos e manipuláveis de forma acéfala.

A interferência social serve como lente, como um prisma que nos ajuda a nos situarmos como humanos, suas regras e funções nos trazem pertencimento e nos auxiliam a vivermos de forma coletiva, mas, não podemos desfigurar tais normas e colocarmos como imutáveis ou ainda como uma escolha de quem queremos ser e de como nos expressarmos dentro de tal contexto, como se as questões sociais pudessem simplesmente ser escolhidas.

[...] a estrutura social condiciona a prática. No entanto, estruturas não são anteriores à vida cotidiana. Estruturas sociais são atualizadas (tornadas hábito) pela atividade humana ao longo do tempo e historicamente criadas. Relações de gênero são atualizadas quando continuamos nos envolvendo em "modos de comportamento generificados", como Carol Hagemann-White (1987) menciona. Estruturas e mudança não são opostos, mas sim parte da mesma dinâmica de nossa vida social. (CONNELL, 2015, p. 157).

As ações de gênero, embasadas por estruturas generificadas, são produto e resultante de especulações sociais acerca das demandas de relações existentes nela. Logo, visualizamos como o sistema econômico influencia diretamente as estruturas familiares, sexuais, interpessoais dentro de uma sociedade. Como Connell (2015) retrata, uma das formas de expor a superioridade de gênero é por meio do assédio sexual (rotineiramente empregado as mulheres) e aqui fazemos nossa relação com os diferentes tipos de assédio (moral, psicológico, verbal etc.) que ocorrem cotidianamente no ambiente de trabalho.

Acreditamos que a base estrutural para a expressão de superioridade de gênero na sociedade é a mesma utilizada para reforçar explorações e supremacia advinda de classes capitalistas. Compre- 
endendo que o capitalismo é generificado, mas sem ter o falso ideário que somente este sistema econômico o é, reforçamos como o mesmo se beneficia com a clara segmentação entre as classes (pois sobrevive da exploração de uma classe sobre a outra) assim como estimular a dominância de um gênero sobre outros, nos auxilia a naturalizar certas explorações e até assédios (SAFFIOTI, 2004).

A violência, em todas as formas, é parte integrante do funcionamento cotidiano da sociedade capitalista - pois é apenas por meio de uma mistura de coersão brutal e consentimento construído que o sistema consegue se sustentar com perfeição. Uma forma de violência que não pode ser impedida sem impedir as outras. (ARRUZZA; BHATTACHARYA; FRASER, 2019, p. 65).

Como vimos o gênero não pode ser visto apenas como algo acoplado a sociedade ou ainda como características que são depositadas nos indivíduos sem desconsiderar as amarras sociais e biológicas, transformando tudo em representações embasadas em discursos. As estruturas de gênero estão entrelaçadas as demais estruturas sociais e, por esse motivo, como brincadeira de barbante "cama de gato", se modificarmos algum de seus apoios, mudamos a configuração da forma envolvida, inquestionavelmente.

\section{Políticas Públicas Educacionais}

Quando o povo participa das decisões da cidade, tendo o aval para isso do Estado, podemos chamar essas ações de políticas públicas (OLIVEIRA, 2010). Assim, as políticas públicas são ações requeridas pela população, mas, para elas serem concretizadas há um consentimento do Estado para tal, dificilmente serão ações que tenham por finalidade exclusiva o bem estar da população com a diminuição dos poderes do Estado.

Então, precisamos deixar claro que essas políticas surgem com a finalidade de apaziguar alguns assuntos ou práticas que estão trazendo transtorno para o convívio em comunidade com o intuito de manter uma ordem social. “Em outras palavras, o processo de formulação de política pública é aquele através do qual os governos traduzem seus propósitos em programas e ações, que produzirão resultados ou as mudanças desejadas no mundo real" (SOUZA, 2003, p. 13).

Não devemos desconsiderar as benesses que as políticas públicas trazem ou podem vir trazer para a vida prática das cidadãs e cidadãos, mas não nos cabe a ingenuidade de acreditar que todas as políticas públicas serão ações que buscam trazer somente melhor qualidade de vida para a população. Podemos caracterizar como o intuito das políticas públicas amenizar as crises que são consequências do sistema capitalista, que abarcar diferentes estruturas como o educacional, ideológico, econômico (PERONI, 2008).

Com o propósito de manter essa hegemonia dos ideais capitalistas e evitar um colapso social, que pode ser resultante das crises constantes que fazem parte do sistema desigual capitalista, o processo educacional busca

[...] a naturalização dos fenômenos para a conciliação social. Para tanto, este projeto educacional hegemônico descentralizou a gestão de sistemas e de unidades escolares, 
centralizou diretrizes curriculares, elevou a educação à condição de importante indicador econômico e social de forma centralizada, por meio de programas de avaliação em larga escala para a educação básica. (PERONI et al., 2009, p. 772, grifo nosso).

Essa busca por naturalizações dos fenômenos e, por que não dizer, de estruturas sociais, são feitas constantemente dentro do processo educacional. As diretrizes e bases educacionais trazem normatizações que devem ser trabalhadas nas escolas, reforçando o que deve ser ensinando ou o que deve continuar de forma obscura na sociedade. Mas, esse processo também não ocorre de forma apática, sobressaindo somente às querências do Estado (RAMOS, 2013). A naturalização ocorre justamente para evitar questionamentos, pois se algo é visto como natural, logo é imutável. Uma das artimanhas do capitalismo para evitar problematizações acerca de suas desigualdades.

Como exemplo da complexidade deste processo e para entendermos que não basta haver uma lei para modificarmos padrões há anos estimulados, podemos citar a Lei 11.646 de 2008. Esta lei traz a obrigatoriedade do estudo da "História e Cultura Afro-Brasileira e Indígena", porém mesmo vindo no formato de obrigatoriedade legislativa, ainda há obstáculos culturais para ela ser posta efetivamente em prática, como podemos ver na reportagem intitulada Professora é substituída após dar aula sobre religião africana em escolar no ceará (FREITAS, 2018). Este caso mostra como pode haver resistências e contradições durante este processo, principalmente se o grupo a ter voz for um grupo dito minoritário da sociedade.

Precisamos repensar o formato de aplicabilidade funcional de políticas para redução de desigualdades, pois o ideário iluminista já se faz démodé há um tempo. Já é sabido que não é o trazer informações e propostas de igualdades que subitamente ocorrerá um processo mágico de queda das desigualdades a tanto enraizadas em nossa sociedade. Arroyo (2010, p. 1386) contribui com este pensamento:

As desigualdades, vistas sem sujeitos, entram apenas como campo de intervenção. Enfatizam-se as desigualdades a corrigir e os deveres do Estado, mas se ignoram os sujeitos, indivíduos e coletivos produzidos como desiguais. A relação privilegiada será Estado, políticas e instituições públicas e correção das desigualdades em abstrato. Sem rostos de sujeitos. (Grifo nosso).

Assim, fica claro que não basta apontarmos para as desigualdades e requerermos e confeccionarmos políticas educacionais (permitidas pelo Estado) que procurem diluir tais assimetrias sociais. A ruptura de anos de inferioridade de coletivos subjulgados, como a superioridade de grupos sociais específicos, demanda de um processo em que enxerguemos cidadãos e cidadãs reais que (re)constroem e são (re)construídos(as) constantemente pelo enredo social.

Devemos olhar para a desigualdade com a magnitude que ela tem, não apenas no meio intraescolar, de forma generalizada, com o intuito apenas de estancar uma situação de desigualdade só neste ambiente (ARROYO, 2010). Pois a criança ou adolescente que sofre discriminação de gênero, não sofre apenas dentro dos muros escolares, como se tal ambiente fosse alheio a realidade social, este grupo que sofre discriminação (como, por exemplo, pelas questões de gênero), deveria ser incentivado a requerer ser tratado de forma igualitária em qualquer contexto social. A escola deve lhe dar essa 
ferramenta de querência e não iludir esse grupo que toda a discriminação será sanada na sociedade, simplesmente por existir uma lei ou uma base nacional curricular.

\section{ABNCC}

Queremos começar este tópico, trazendo uma relação direta de tudo que já fora dito neste artigo com a importância do ambiente escolar para o processo de socialização. A instituição escolar é um importante local de aprendizagem e renovação de conteúdos científicos como também sociais. Esse processo de ensino e aprendizagem formal demanda constante formatação, constatação e avaliação para ser realizado com efetiva funcionalidade, para o Estado.

Com o intuito de ter uma padronização no processo educacional, um plano e uma base nacional começaram a serem almejados na Era Vargas, época em que o Brasil buscava fortalecer sua identidade (VIEIRA; RAMALHO; VIEIRA, 2017). Reforçando como as escolas são importantes instituições socializadoras. Após as organizações políticas e mudanças no cenário nacional, em 1962 surgiu o primeiro Plano Nacional de Educação, porém ainda sem as bases curriculares para todo o território brasileiro.

Em 1967, em pleno regime militar, tivemos a confecção da Constituição Federativa. Nela temos mais uma menção às Bases educacionais em seu artigo 8 onde eram ditas as competências direcionadas à União, entre as funções tínhamos:

I - manter relações com Estados estrangeiros e com eles celebrar tratados e convenções; participar de organizações internacionais;

II - declarar guerra e fazer a paz;

III - decretar o estado de sitio;

VII - organizar e manter a policia federal com a finalidade de prover:

c) a apuração de infrações penais contra a segurança nacional, a ordem política e social, ou em detrimento de bens, serviços e interesses da União, assim como de outras infrações cuja prática tenha repercussão interestadual e exija repressão uniforme, segundo se dispuser em lei;

XIV - estabelecer planos nacionais de educação e de saúde;

XVII - legislar sobre:

d) Produção e consumo;

l) política de crédito, câmbio, comércio exterior e interestadual; transferência de valores para fora do Pais;

q) diretrizes e bases da educação nacional; normas gerais sobre desportos.

Durante este período da ditadura civil militar, houve uma abertura para investimentos e empréstimos internacionais, como também uma logística de mercado no âmbito educacional. 0 que repercutiu nos financiamentos na área da educação e nos seus objetivos. Tendo um constante estreitamento entre mercado e educação (SAVIANI, 2008). 
Após a perda de força do regime militar, na década de 1980, houve uma nova constituição federativa em 1988 que ainda trazia a importância de uma base nacional educacional. Como podemos ver em seu artigo 22: "Compete privativamente à União legislar sobre: XXIV - diretrizes e bases da educação nacional;” (BRASIL, 1988, on-line).

Em consequência as modificações políticas no Brasil, em 1996 foi estabelecida a nova Lei de Diretrizes e Bases da Educação Nacional (LDB), neste documento temos o reforço da coligação do mercado de trabalho com o setor educacional, institucionalizado enquanto lei, como demonstra seu artigo $1^{\circ} \S 2^{\circ}$ "A educação escolar deverá vincular-se ao mundo do trabalho e à prática social” (BRASIL, 1996, on-line ). A LDB também trazia a importância de um plano nacional para a educação como uma base curricular única:

Art. 9. A União incumbir-se-á de: I - elaborar o Plano Nacional de Educação, em colaboração com os Estados, o Distrito Federal e os Municípios;

Art. 26. Os currículos do ensino fundamental e médio devem ter uma base nacional comum, a ser complementada, em cada sistema de ensino e estabelecimento escolar, por uma parte diversificada, exigida pelas características regionais e locais da sociedade, da cultura, da economia e da clientela. (BRASIL, 1996, on-line).

Para providenciar algumas necessidades emergenciais, na década de 1990 foram inseridos no contexto educacional os Parâmetros Curriculares Nacionais. Esses parâmetros não supriam as funcionalidades idealizadas pela base nacional curricular, como a própria nomenclatura do documento retrata (um serve como comparação e ou outro como suporte), mas serviram como uma ponte importante para este processo.

Assim, em 2014, após 9 anos, e depois de muitos debates e desdobramentos, tivemos o novo Plano Nacional de Educação (PNE) que trazia diretrizes, metas e estratégias para os próximos dez anos. Lembrando que o cenário político brasileiro neste momento era de instabilidade econômica onde a presidenta Dilma encontrava-se em queda de popularidade. E, por este motivo, o PNE 2014-2024 foi realizado baseado em negociações, evitando embates políticos e favorecendo a maleabilidade de ideias, tendo em vista as eleições presidenciáveis que ocorreriam no final do ano de 2014 (RAMALHO; VIEIRA, 2019).

Logo, este plano reforça questões, relacionando educação com o mercado de trabalho ("art $2^{\circ}$ $\checkmark$ - formação para o trabalho e para a cidadania, com ênfase nos valores morais e éticos em que se fundamenta a sociedade"), como evita mencionar pontos polêmicos (não há a utilização da palavra gênero em todo o documento).

E, após mais quatro anos, tivemos a tão sonhada Base Nacional Comum Curricular (BNCC) do sistema educacional brasileiro, estamos considerando aqui a versão completa e final deste documento, após debates, embates e disputas, a redação final da BNCC foi trazida no final de 2018 . Sendo definida como

[...] um documento de caráter normativo que define o conjunto orgânico e progressivo de aprendizagens essenciais que todos os alunos devem desenvolver ao longo das etapas e modalidades da Educação Básica, de modo a que tenham assegurados seus direitos de aprendizagem e desenvolvimento, em conformidade com o que preceitua o Plano Nacional de Educação (PNE). (BRASIL, 2018, p. 7). 
Importante destacar que no final do ano de 2018 foram realizadas eleições presidenciáveis onde um candidato com discurso ultra conservador e que possuía o slogan "Brasil acima de tudo, Deus acima de todos" foi vencedor do plebiscito, mostrando como uma corrente com ideais de extrema direita e conservadores estavam latentes socialmente. Acreditamos que, por esse motivo, a BNCC segue esta lógica e esse formato, priorizando o mundo do trabalho, tendo suas competências, conhecimentos e habilidades direcionadas para o mesmo, e desconsiderando debates acerca de assuntos ditos polêmicos. Seguindo o padrão do PNE 2014-2024, a BNCC não utiliza a palavra gênero, voltada para as questões da estrutura de gênero na sociedade.

\subsection{A BNCC GENERIFICADA - O SILÊNCIO QUE DIZ}

A BNCC, como já vimos, não faz menção direta as estruturas generificadas. Para sermos mais precisos, no documento aparece a palavra gênero(s) 329 vezes, porém todas elas relacionadas a questões literárias, musicais ou gramaticais. Porém, não podemos desconsiderar o que não foi trazido de forma clara neste documento. Na falta da palavra gênero, dentro do debate humano do termo, buscamos por palavras que poderiam retratar uma busca por um currículo preocupado com as desigualdades de gênero na sociedade, mesmo que de maneira indireta. Nossos achados para palavras alternativas foram esses: Trabalho - 221; Diversidade - 188; respeito - 174; Direitos Humanos - 64; Cidadania - 58; Preconceito(s) - 54; Violência - 18; Homem - 3; Mulher(es) - 2; Feminino - 2.

Nossa interpretação sobre as palavras investigadas e achadas têm relação com toda a base teórica que estamos nos embasando neste artigo. De forma sucinta, relembraremos os principais pontos com o intuito de facilitar a compreensão da nossa visão: apontamos que o regime educacional e de gênero estão relacionados e fazem parte diretamente das estruturas sociais, estruturas essas que tem outro forte pilar, a economia. Quando falamos em economia e gênero, gostaríamos que a visão de uma segmentação simplista da separação de trabalho, onde mulheres ficam em casa e homens trabalhando em fábricas, fosse evitada.

0 mundo do trabalho abarca uma relação geracional complexa e muitas vezes vista de forma reducionista, como as estruturas de gênero diminuídas e o campo educacional negligenciado. Nenhum desses adjetivos deve ser visto de forma aleatória, se analisarmos nossa realidade social comprovaremos como tais estruturas são intencionalmente (re)produzidas, não apenas no senso comum (o que já é um importante balizador cultural), mas nas academias e pelos estudiosos.

O trabalho remunerado, no sistema capitalista, é embasado na exploração (em maior ou menor grau) das trabalhadoras e trabalhadores, como explica Moreira (2019, p. 126)

As relações econômicas, mais do que somente uma relação de conflitos de classes, passaram a ser uma relação entre capital e trabalho. E cada vez mais aqueles que não geram riquezas ficavam com uma parcela maior, e os que eram responsáveis pela criação de riquezas [trabalhador(a)], como uma parcela menor. Em resumo, a exploração do trabalho pelos donos dos meios de produção. (Grifo nosso). 
Este também é o ideal das relações de gênero na sociedade capitalista. E ambos com o intuito de naturalizar e evitar discussões e debates sobre essa estrutura na sociedade. Dentro da instituição socializadora escola, por meio de seus currículos, bases e leis, esta naturalização pode ser reforçada ou questionada.

Logo, quando trazemos uma analise quantitativa das palavras que aparecem na BNCC e temos uma distorção de 221 palavras "trabalho" e 2 palavras relativas a "mulheres" e 3 a "homem", precisamos compreender o que este documento está falando sobre o mundo do trabalho (capitalista), sobre as relações de gênero (machista) e o campo educacional (conservadora). A manutenção desta logística continua beneficiando pequenos grupos e valorizando as desigualdades existentes na nossa sociedade.

Desta forma, fica mais legível que a BNCC, mesmo sem usar o termo gênero nenhuma vez em seu texto, a base fala (e muito) sobre as estruturas de gênero. Esta política pública educacional não foge de sua função normatizadora (PERONI et al., 2009) e reforça as explorações já existentes no contexto social. Para Saffioti (2004, p. 131) “[...] a submissão das mulheres na sociedade civil assegura o reconhecimento do direito patriarcal dos homens", e reforçamos esta frase dando magnitude ao "nó" citado pela autora: a submissão de um grupo dito inferior assegura o reconhecimento e o poder de exploração dos reconhecidos como superiores.

Importante reforçar que esse processo não ocorre de forma apática, mas se torna, cada vez mais, tão naturalizado e intrínseco a sociedade que muitas vezes não visualizamos relações sociais sem essa contextualização. As estruturas sociais reforçam as suas práticas (CONNELL, 2015), reforçam feitos e ações. Não necessariamente num conceito de consciente ou inconsciente, mas sim na ideia de pertencer a uma sociedade, de suas regras, padrões e leis. Ações essas que nos empurram a ceder, para preservarmos a vida, gerando uma falsa ideia de consentimento. Saffioti $(2004$, p. 118) nos traz um exemplo que auxilia neste entendimento:

Se uma mulher ameaçada de estupro por um homem armada, e resolve, racionalmente, ceder, a fim de preservar o bem maior, ou seja, a vida, sua atitude atuará contra ela perante o Direito brasileiro, cujos fundamentos são positivistas, ou seja, os mesmos que informam o (neo)liberalismo. 0 juis interpretaria a cessão como consentimento.

Na sociedade atual é essencial manter o ideário que existem espécies/grupos/classes que devem ser cerceadas em seus direitos, sendo diminuídas e que, por isso, devem ceder para preservar a vida, mesmo que essa vida seja miserável, onde seja necessário se conformar com restos produzidos por outras espécies/grupos/classes. Essa lógica serve para ratos, mulheres, trabalhadores(as) e para quem mais se encaixar no local de subalternização.

Qualquer ensino que não fale sobre essa logística de submissão, que não discorra sobre essas problematizações, está sendo favorável a ela, favorecendo o opressor (seja ele quem for). Pois, o que interessa ao opressor '[...] é a permanência delas em seu estado de 'imersão' em que, de modo geral, se encontram impotentes em face da realidade opressora, como 'situação limite' que lhes parece intransponível” (FREIRE, 2011, p. 54).

Assim, fica claro que a BNCC não só fala, mas grita sobre a estrutura de gênero na sociedade, exclama pela sua manutenção, pela sua inquestionalidade e sua intransponibilidade. Sendo generificada, como toda ação humana. 


\section{REFLEXÕES}

Nosso maior desafio neste artigo foi trazer as relações entre trabalho, gênero e educação, mostrando as suas interseções, o que une essas estruturas na totalidade social. Pois, a continuidade em segmentar esses campos só beneficia a falta de compreensão de todo o processo social. Não há uma ordem de prioridade entre ambos. Eles estão interligados tão intimamente que podem chegar a nos confundir se não olharmos de forma atenta.

Importante salientar que as ações não são apenas depositadas nos cidadãos e cidadãs, esse processo é engenhoso e, por vezes, nos parece tão intrínseco e natural que se torna a única forma de se relacionar na sociedade. A exploração é a palavra chave que norteia o atual sistema, que direciona as demandas educacionais que são ministradas e consentidas pelo Estado em forma de políticas públicas educacionais. Tendo como principal objetivo regular as engrenagens de uma sociedade que deve se conformar em ser dividida em grupos de oprimidos(as) e opressores(as).

Assim, com este fervilhar de pensamentos, buscamos contribuir para uma visão crítica, generificada, humanizadora e humanizante destes processos. Com a preocupação não de "levar luz" e conhecimento, mas de auxiliar a reforçar possibilidades de práticas educacionais e sociais que destoam das desigualdades e reforçam a importância e a magnitude de termos relações igualitárias no trabalho e nas questões ligadas a gênero.

Enfim, que essas linhas sirvam para novas análises sobre a temática gênero como para as suas funcionalidades dentro das políticas públicas educacionais, sendo vista na sua devida importância, sem ser negligenciada de um processo de igualdade social que muitos almejam, mas que se esquecem que esse processo depende de ações diárias que a fortifica e a torna possível.

\section{REFERÊNCIAS}

ARRUZZA, Cinzia; BHATTACHARYA, Tithi; FRASER, Nancy. Feminismo para os 99\%: um manifesto. São Paulo: Boitempo, 2019.

ARROYO, Miguel G. Políticas educacionais e desigualdades: à procura de novos significados. Educ. Soc., Campinas, v. 31, n. 113, p. 1381-1416, dez. 2010. Disponível em: http://dx.doi.org/10.1590/ S0101-73302010000400017. http://www.scielo.br/scielo.php?script=sci_arttext\&pid=S0101$73302010000400017 \&$ lng=en\&nrm=iso. Acesso em: 10 jan. 2020.

BRASIL. Constituição Federal (1967). Emenda Constitucional no 1, de 17 de outubro de 1969. Disponível em: http://www.planalto.gov.br/ccivil_03/constituicao/constituicao67.htm. Acesso em: 9 jan. 2020. 
BRASIL. Constituição Federal (1988). Emenda Constitucional n0 59, de 11 de novembro de 2009. Disponível em: http://www.planalto.gov.br/ccivil_03/constituicao/constituicaocompilado.htm. Acesso em: 9 jan. 2020.

BRASIL. Lei de Diretrizes e Bases da Educação Nacional. Lei no 9.394, de 20 de dezembro de 1996. Disponível em: http://portal.mec.gov.br/seesp/arquivos/pdf/lei9394_ldbn1.pdf. Acesso em: 9 jan. 2020.

BRASIL. Lei n.13.005, de 25 de junho de 2014. Aprova o Plano Nacional de Educação - PNE e dá outras providências. Diário Oficial da União, Brasília, DF., 26 jun 2014a. Disponível em: http://www. planalto.gov.br/ccivil_03/_ato2011-2014/2014/lei/l13005.htm Acesso em: 9 jan. 2020.

BRASIL. Base Nacional Comum Curricular - Educação é a base, 2018. Disponível em: http:// basenacionalcomum.mec.gov.br/images/BNCC_EI_EF_110518_versaofinal_site.pdf.

Acesso em: 9 jan. 2020

CONNELL, Raewy; PEARSE, Rebeca. Gênero: uma perspectiva global. São Paulo: nVersos, 2015.

FREIRE, Paulo. Pedagogia do oprimido. Rio de Janeiro: Paz e Terra, 2011.

FREITAS, Cinthia. Professora é substituída após dar aula sobre religião africana em escolar no Ceará. G1 CE, 9 de maio de 2018. Disponível em: https://g1.globo.com/ce/ceara/noticia/professora-esubstituida-apos-dar-aula-sobre-religiao-africana-em-escola-no-ceara.ghtml. Acesso em: 8 jan. 2020.

GIL, Antônio Carlos. Métodos e técnicas de pesquisa social. São Paulo: Atlas, 2008.

MOREIRA, Eduardo. Desigualdade \& caminhos para uma sociedade mais justa. Rio de Janeiro: Civilização Brasileira, 2019.

OLIVEIRA, A. F. Políticas públicas educacionais: conceito e contextualização numa perspectiva histórica. In: OLIVEIRA, A. F.; PIZZIO, A.; FRANÇA, G. (org.). Fronteiras da educação: desigualdades, tecnologias e políticas. Goiás: PUC Goiás, 2010. p. 93-99.

PERONI, Vera Maria Vidal. A autonomia docente em tempos de Neoliberalismo e Terceira Via. Seminário Internacional de Formação de Professores para o Mercosul/ConeSul, 16, 2008. Anais [...], Universidade Nacional de Luján, Buenos Aires, Argentina, 2008

PERONI, Vera Maria Vidal et al. Estado e terceiro setor: as novas regulações entre o público e o privado na gestão da educação básica brasileira. Educação Sociedade. Campinas, v. 30, n. 108, p. 761-778, out. 2009. 
RAMALHO, Carla Chagas; VIEIRA, José Jairo. Do projeto de Lei 8.035/2010 à Lei 13.005/2014: a inviabilização da temática gênero. TEXTURA, v. 22, n. 48, p. 179- 201, out.-dez. 2019. DOI: https:// doi.org/10.17648/textura-2358-0801-21-48-5254. Disponível em: http://www.periodicos.ulbra.br/ index.php/txra/article/view/5254/3584. Acesso em: 9 jan. 2020

RAMOS, Géssica Priscila. A escola contemporânea e sua identidade (ou sobre o óbvio esquecido). Revista HISTEDBR, Campinas, n. 49, p. 350-362, mar. 2013.

SAFFIOTI, Heleieth I. B. Gênero, patriarcado, violência. São Paulo: Editora Fundação Perseu Abramo, 2004.

SAVIANI, Dermeval. O legado educacional do regime militar. Caderno Cedes, v. 28, n. 76, p. 291-312, set.-dez. 2008.

SOUZA, Celina. Políticas públicas: questões temáticas e de pesquisa. Caderno CRH, Salvador, n. 39, jul.-dez. 2003

VIEIRA, José Jairo; RAMALHO, Carla Chagas; VIEIRA, Andréa Lopes da Costa. A origem do plano nacional de educação e como ele abordou as questões de gênero. Revista online de Política e

Gestão Educacional, [S.l.], p. 64-80, jan. 2017. ISSN 1519-9029. DOI: https://doi.org/10.22633/ rpge.v21.n1.2017.9746. Disponível em: https://periodicos.fclar.unesp.br/rpge/article/ view/9746/6592. Acesso em: 8 jan. 2020. 
1 Mestre em Educação - UFRJ; Especialista em Gênero e Sexualidade - UERJ; Graduada em Educação Física UERJ; Professora efetiva do Departamento de Educação Física e Desporto - UNIMONTES.

E-mail: carlaramalho.ccr@gmail.com

2 Doutor em Sociologia - IUPERJ; Mestre em Ciências do Esporte - UERJ; Graduado em Educação Física e em Ciências Sociais - UERJ; Professor Associado da Faculdade de Educação e do Programa de Pós-Graduação em Educação (PPGE) -UFRJ. E-mail: carlaramalho.ccr@gmail.com

\section{(). (1) (-)}

Este artigo é licenciado na modalidade acesso abertosob a Atribuição-Compartilhalgual CC BY-SA

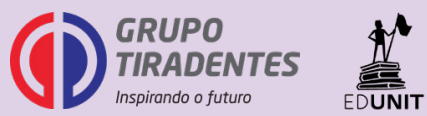

